\title{
Increased killing of SCCVII squamous cell carcinoma cells after the combination of Pc 4 photodynamic therapy and dasatinib is associated with enhanced caspase-3 activity and ceramide synthase 1 upregulation
}

\author{
DUSKA SEPAROVIC ${ }^{1,2}$, PAUL BREEN ${ }^{1}$, NITHIN B. BOPPANA ${ }^{1}$, ERIC VAN BUREN ${ }^{2}$, NICHOLAS JOSEPH $^{1}$, \\ JACQUELINE M. KRAVEKA ${ }^{3}$, MEHRDAD RAHMANIYAN ${ }^{3}$, LI LI $^{3}$, TATYANA I. GUDZ ${ }^{4}$, ALICJA BIELAWSKA ${ }^{5}$, \\ AIPING BAI ${ }^{5}$, JACEK BIELAWSKI ${ }^{5}$, JASON S. PIERCE ${ }^{5}$ and MLADEN KORBELIK ${ }^{6}$ \\ ${ }^{1}$ Department of Pharmaceutical Sciences, Eugene Applebaum College of Pharmacy and Health Sciences, \\ and ${ }^{2}$ Karmanos Cancer Institute, Wayne State University, Detroit, MI $48201 ;{ }^{3}$ Department of Pediatrics, \\ Division of Hematology-Oncology, Charles Darby Children's Research Institute, and Hollings Cancer Center, \\ ${ }^{4}$ Ralph H. Johnson Veterans Affairs Medical Center, and Department of Neuroscience, \\ ${ }^{5}$ Department of Biochemistry and Molecular Biology, Medical University of South Carolina, \\ Charleston, SC 29425, USA; ${ }^{6}$ British Columbia Cancer Agency, Vancouver, BC V5Z 1L3, Canada
}

Received August 9, 2013; Accepted September 6, 2013

DOI: 10.3892/ijo.2013.2132

\begin{abstract}
Photodynamic therapy (PDT) is not always effective as an anticancer treatment, therefore, PDT is combined with other anticancer agents for improved efficacy. The combination of dasatinib and PDT with the silicone phthalocyanine photosensitizer Pc 4 was assessed for increased killing of SCCVII mouse squamous cell carcinoma cells, a preclinical model of head and neck squamous cell carcinoma, using apoptotic markers and colony formation as experimental end-points. Because each of these treatments regulates the metabolism of the sphingolipid ceramide, their effects on mRNA levels of ceramide synthase, a ceramide-producing enzyme, and the sphingolipid profile were determined. PDT + dasatinib induced an additive loss of clonogenicity. Unlike PDT alone or PDT + dasatinib, dasatinib induced zVAD-fmk-dependent cell killing. PDT or dasatinib-induced caspase-3 activation was potentiated after the combination. PDT alone induced mitochondrial depolarization, and the effect was inhibited after the combination. Annexin $\mathrm{V}^{+}$and propidium iodide ${ }^{+}$ cells remained at control levels after treatments. In contrast to PDT alone, dasatinib induced upregulation of ceramide synthase $1 \mathrm{mRNA}$, and the effect was enhanced after the
\end{abstract}

Correspondence to: Dr Duska Separovic, Department of Pharmaceutical Sciences, Eugene Applebaum College of Pharmacy and Health Sciences, Wayne State University, 259 Mack Ave., Detroit, MI 48201, USA

E-mail: dseparovic@wayne.edu

Key words: apoptosis, ceramide, ceramide synthase, ceramidase, dasatinib, PDT, sphingolipids, sphingosine combination. Dasatinib induced a modest increase in C20:1and C22-ceramide but had no effect on total ceramide levels. PDT increased the levels of 12 individual ceramides and total ceramides, and the addition of dasatinib did not affect these increases. PDT alone decreased substantially sphingosine levels and inhibited the activity of acid ceramidase, an enzyme that converts ceramide to sphingosine. The data suggest that PDT-induced increases in ceramide levels do not correlate with ceramide synthase mRNA levels but rather with inhibition of ceramidase. Cell killing was zVAD-fmk-sensitive after dasatinib but not after either PDT or the combination and enhanced cell killing after the combination correlated with potentiated caspase- 3 activation and upregulation of ceramide synthase 1 mRNA but not the production of ceramide. The data imply potential significance of the combination for cancer treatment.

\section{Introduction}

Photodynamic therapy (PDT), a non-invasive cancer treatment modality, can effectively eradicate local malignancies. PDT utilizes a light-absorbing photosensitizer, visible light and oxygen to generate reactive oxygen species that destroy malignant cellular targets (1). However, because tumors recur, PDT needs to be optimized to improve its therapeutic benefit. Dasatinib, a multi-kinase inhibitor, is an anticancer agent that has been successfully used for treatment of chronic myeloid leukemia (2). As a single agent evaluated in clinical trials for treatment of solid tumors, including advanced head and neck squamous cell carcinoma (HNSCC), however, dasatinib has not been shown to be successful (3). In combination with other chemotherapeutic agents or radiation dasatinib is a more effective anticancer treatment in vitro, in vivo and in clinical trials (4-7). 
Bioactive sphingolipids have been implicated in drugand radiation-resistance, therefore targeting sphingolipid metabolism can contribute to increased effectiveness of the current treatment strategies (8). As shown in Fig. 1, the sphingolipid ceramide is generated in the de novo biosynthesis pathway, which includes a ceramide synthase-dependent addition of a fatty acyl group to dihydrosphingosine to form dihydroceramide. Ceramide is formed from dihydroceramide by a desaturase-dependent insertion of a double bond in the sphingosine backbone. Six mammalian ceramide synthases have been identified with distinct specificity for fatty acyl CoAs and functions (9). For example, C18- and C16-ceramide, containing an 18- and 16-carbon fatty acid, are generated by ceramide synthase 1 and 6, respectively, and induce HNSCC suppression and proliferation, respectively (10). Ceramide is deacylated by ceramidase, giving rise to sphingosine, and sphingosine is acted upon by sphingosine kinase to give rise to sphingosine-1-phosphate (S1P), an antiapoptotic sphingolipid.

We demonstrated that the knockdown of ceramide synthase 1 or 6 is associated with reduction in ceramides and dihydroceramides resulting in apoptotic resistance to PDT with Pc $4(11,12)$. Dasatinib induces apoptosis via upregulation of ceramide synthases, including increased expression of ceramide synthase 1 gene (13). The combination of dasatinib and PDT with Pc 4 was tested for potential anticancer efficacy in SCCVII mouse squamous cell carcinoma cells, a preclinical model of HNSCC (14), using apoptotic markers, colony formation and ceramide metabolism as experimental end-points.

\section{Materials and methods}

Materials. The phthalocyanine photosensitizer $\mathrm{Pc} 4$, HOSiPcOSi $(\mathrm{CH} 3)_{2}(\mathrm{CH} 2)_{3} \mathrm{~N}\left(\mathrm{CH}_{3}\right)_{2}$, was supplied by $\mathrm{Dr}$ Malcolm E. Kenney (Department of Chemistry, Case Western Reserve University, Cleveland, OH, USA). N-[9,10$\left.{ }^{3} \mathrm{H}\right] \mathrm{D}$-e-C16-ceramide was synthesized at the Lipidomics Shared Resource (Medical University of South Carolina, Charleston, SC, USA). RPMI medium and serum were from Life Technologies (Carlsbad, CA, USA) and Hyclone (Logan, UT, USA), respectively. The inhibitors zVAD-fmk and dasatinib (BMS-354825) were from MBL International (Woburn, MA, USA) and Selleck Chemicals (Houston, TX, USA), respectively.

Cell culture and treatments. SCCVII cells, initially derived from the spontaneous abdominal wall tumor of a $\mathrm{C} 3 \mathrm{H}$ mouse (15), were grown in RPMI medium containing $10 \%$ fetal bovine serum, $100 \mathrm{U} / \mathrm{ml}$ penicillin and $100 \mu \mathrm{g} / \mathrm{ml}$ streptomycin (Life Technologies). Cells were maintained at $37^{\circ} \mathrm{C}$ in a $5 \% \mathrm{CO}_{2}$ atmosphere and were treated in the growth medium. For PDT experiments, after overnight incubation with Pc 4 at $37^{\circ} \mathrm{C}$, cells were irradiated with red light $\left(2 \mathrm{~mW} / \mathrm{cm}^{2} ; \lambda_{\max } \sim 670 \mathrm{~nm}\right)$ using a light-emitting diode array light source (EFOS, Mississauga, ON, Canada) at the fluence of $200 \mathrm{~mJ} / \mathrm{cm}^{2}$ at room temperature and then incubated at $37^{\circ} \mathrm{C}$ for indicated periods of time. For PDT + dasatinib, dasatinib was added to the cells $22 \mathrm{~h}$ prior to irradiation, unless indicated otherwise. After treatments, cells were collected on ice and processed for various analyses. For mass spectroscopy (MS) analysis, cells were washed twice with cold phosphate-buffered saline (Corning Life Sciences,

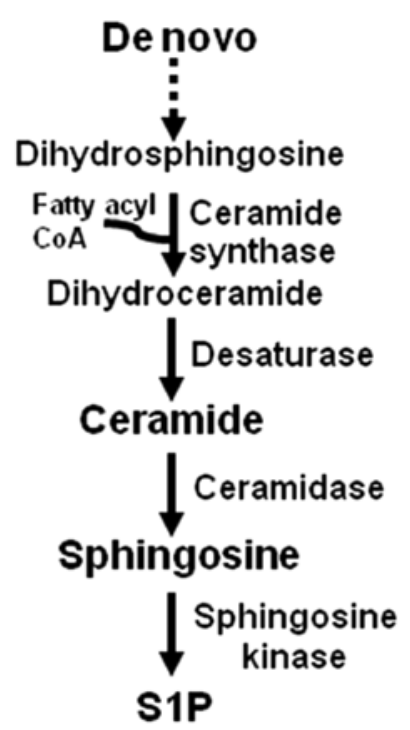

Figure 1. Ceramide metabolism.

New York, NY, USA), resuspended in the mixture of ethyl acetate/methanol (1:1, v/v; EMD Chemicals, Billercia, MA, USA), dried under nitrogen and shipped overnight on dry ice to the Lipidomics Shared Resource (Medical University of South Carolina, SC, USA) for further processing.

Electrospray ionization/double mass spectrometry (MS) analysis. After extraction, sphingolipids were separated by high performance liquid chromatography, introduced to electrospray ionization source and then analyzed by double MS using TSQ Quantum Access Max triple stage quadrupole mass spectrometer (Thermo-Fisher Scientific, Pittsburg, PA, USA) as described previously (16).

RNA extraction and quantitative real-time polymerase chain reaction $(R T-P C R)$. Total RNA isolation was performed with RNeasy ${ }^{\circledR}$ Mini kit (Qiagen, Valencia, CA, USA) according to the manufacturer's instructions. cDNA was synthesized from $1 \mu \mathrm{g}$ of the total RNA using iScript ${ }^{\mathrm{TM}}$ cDNA Synthesis kit (Bio-Rad, Hercules, CA, USA). The concentration and quality of total RNA preparations were evaluated spectrophotometrically. RT-PCR was performed on a Bio-Rad CFX96 detection system using Bio-Rad SsoFast Probes Supermix ${ }^{\mathrm{TM}}$ and TaqMan ${ }^{\circledR}$ Gene Expression Assays (Life Technologies) with the primers for ceramide synthases $1,2,4,5,6$, the housekeeping gene products RPL37A and hypoxanthine-guanine phosphoribosyltransferase (HGPRT), and the fluorophore probe FAM-490 (6-carboxyflurescein; all obtained from Life Technologies). Initial steps of RT-PCR were $30 \mathrm{sec}$ at $85^{\circ} \mathrm{C}$, followed by 40 cycles consisting of a $5 \mathrm{sec}$ at $95^{\circ} \mathrm{C}$, followed by $10 \mathrm{sec}$ at $60^{\circ} \mathrm{C}$. Determination of the relative normalized expression of corresponding ceramide synthase mRNAs against the expression of housekeeping gene-encoded proteins RPL37A and HGPRT was performed by $\Delta \Delta \mathrm{C}_{\mathrm{T}}$ provided by CFX96 manager software 3.0 from Bio-Rad.

Acid ceramidase activity assay. Acid ceramidase activity was performed as described previously (17). Cells were lysed under acidic condition ( $\mathrm{pH} 4.5)$. Equal amounts of $\mathrm{N}-\left[9,10-{ }^{3} \mathrm{H}\right]$ 

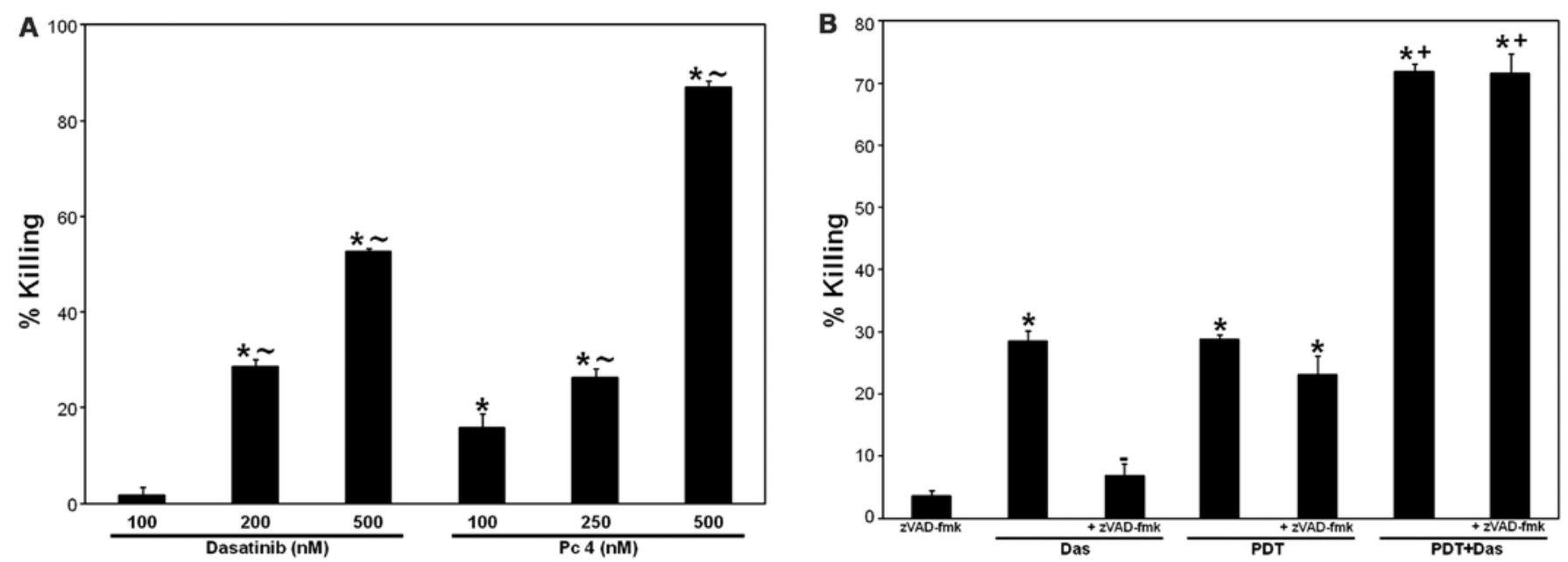

Figure 2. (A) PDT and dasatinib, respectively, induce dose-dependent cell killing. (B) Effect of zVAD-fmk on PDT \pm dasatinib-induced cell killing. SCCVII cells were plated after appropriate dilutions into P60-mm dishes and allowed to attach overnight in the growth medium. For PDT, cells were plated in the growth medium containing Pc 4 at the indicated concentrations (A) or at $250 \mathrm{nM}(\mathrm{B})$, incubated overnight at $37^{\circ} \mathrm{C}$, and irradiated with red light $\left(200 \mathrm{~mJ} / \mathrm{cm}^{2}\right)$. (B) $\mathrm{zVAD}$ fmk $(25 \mu \mathrm{M})$, was added $1 \mathrm{~h}$ prior to treatments; For PDT + dasatinib, dasatinib $(200 \mathrm{nM})$ was added immediately prior to irradiation. (A and B) After 8-10 days of growth at $37^{\circ} \mathrm{C}$, colonies ( $\geq 50$ cells) were stained with crystal violet $(0.1 \%)$ and counted. The data are expressed as the percentage of killing and are shown as the mean \pm SEM, $n=3-12$. The significance $(\mathrm{p}<0.05)$ is shown as follows: difference between corresponding doses of dasatinib or PDT; "treated are different from untreated control; ${ }^{+}$(PDT + dasatinib) is different from PDT or dasatinib alone; 'zVAD-fmk is different from dasatinib alone. Das, dasatinib.

D-e-C16-ceramide were mixed with $0.2 \%$ Triton X-100 and $0.4 \%$ cholate and dried down under nitrogen. The lipid film was dissolved by mixing and sonication in deionized water. After additions of acidic assay buffer $(0.2 \mathrm{M}$ acetic acid, $0.2 \mathrm{M}$ sodium acetate and $0.5 \%$ Triton $\mathrm{X}-100, \mathrm{pH} 4.5$ ) and cell lysate, the reaction was carried at $37^{\circ} \mathrm{C}$ for $1 \mathrm{~h}$ and stopped by adding Dole's alkaline solution. $\left[{ }^{3} \mathrm{H}\right]$ palmitic acid, a hydrolytic product of acid ceramidase, was extracted and processed to calculate the enzyme activity (17). Quantitation of radioactivity was performed using LS 6500 multipurpose scintillation counter (Beckman Coulter, Brea, CA, USA).

DEVDase (caspase-3) activity assay. As described previously (18), DEVDase activity was determined in the cytosol by an assay based on the enzyme's cleavage of a fluorogenic derivative of the tetrapeptide substrate N-acetyl-Asp-Glu-Val-Asp (DEVD; Enzo Life Sciences, Farmingdale, NY, USA). The peptide sequence is based on the cleavage site $\mathrm{Asp}^{216}$ of the caspase-3 substrate poly(ADP-ribose) polymerase (PARP). The fluorescence of the cleaved DEVD substrate was measured using a spectrofluorometer (F-2500 Hitachi, New York, NY, USA; $380 \mathrm{~nm}$ excitation, $460 \mathrm{~nm}$ emission).

Mitochondrial depolarization measurement. The lipophilic cationic dye JC-1 (5,5',6,6'-tetrachloro-1,1'3,3'-tetraethylbenzimidazolylcarbocyanine iodide; BD Biosciences, San Diego, CA, USA) was used to determine mitochondrial membrane potential by flow cytometry, as we described previously $(11,19,20)$. After treatments, cells were harvested and processed for flow cytometry according to the manufacturer's instructions (BD Biosciences). BD LSR II flow cytometer was used for analysis (BD Biosciences).

Apoptosis detection. As previously described $(11,20,21)$, to detect apoptosis, the exposure of phosphatidylserine in the outer leaflet of the cell membrane and cell membrane integrity loss were measured using Annexin $\mathrm{V}$ and DNA-binding propidium iodide fluorescent dyes (BD Biosciences), respectively. Early apoptotic (Annexin $\mathrm{V}^{+} /$propidium iodide) were distinguished from late apoptotic or necrotic cells (Annexin $\mathrm{V}^{+}$/propidium iodide ${ }^{+}$). The kit was obtained from BD Biosciences and the flow cytometric protocol was followed, as described by the manufacturer.

Clonogenic assay. Long-term cell viability was assessed using clonogenic assay according to the modified protocol that we described previously (20). Plating density was 250 cells/plate. Plating efficiency was $34 \%(\mathrm{n}=16)$.

Protein determination. Protein content was determined by a modified Bradford assay (Bio-Rad) or, for acid ceramidase assay, by a bicinchoninic acid protein assay kit (ThermoFisher Scientific).

Statistical analysis. Data are shown as the mean \pm SEM. Statistical analyses were performed by Student's t-test. Significance was defined as a two-tailed $\mathrm{p}<0.05$.

\section{Results}

$P D T+$ dasatinib enhances overall cell killing. Effect of zVADfmk on PDT \pm dasatinib-induced cell killing. To test whether killing of SCCVII cells is increased by the combination of Pc 4-PDT with dasatinib, colony formation assay was used as the experimental end-point. The treatments were first used as single agents to determine whether they induce dose-dependent cell killing. Incubation of SCCVII cells with 100, 200 and $500 \mathrm{nM}$ dasatinib led to 2, 28 and $53 \%$ cell killing, respectively (Fig. 2A). Similarly, PDT with 100,250 or $500 \mathrm{nM} \mathrm{Pc} \mathrm{4,} \mathrm{at}$ the light fluence of $200 \mathrm{~mJ} / \mathrm{cm}^{2}$, induced 16,26 and $87 \%$ cell killing, respectively (Fig. 2A). Treatment of cells with the combination of PDT and dasatinib, each used at LD $<30$, led 

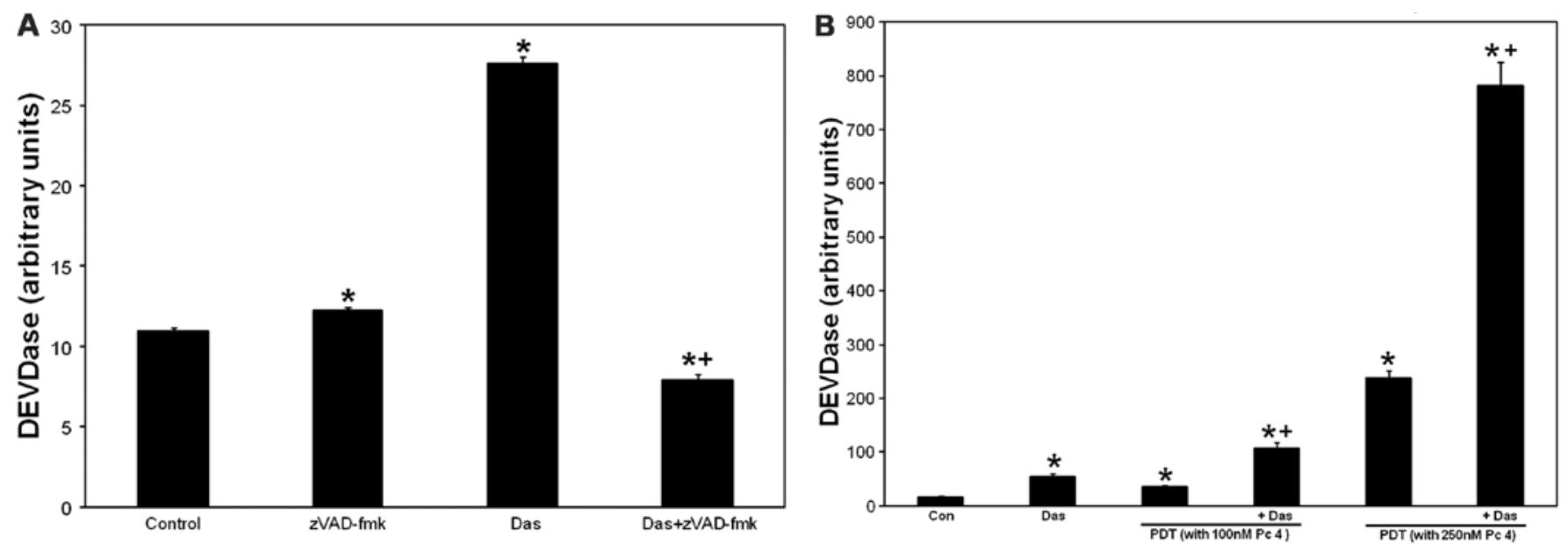

Figure 3. (A) Dasatinib-induced caspase-3 activation is abolished by zVAD-fmk. (B) PDT- or dasatinib-induced caspase-3 activation is potentiated after PDT + dasatinib.

to $72 \%$ cell killing, which was significantly greater than that of each treatment alone (Fig. 2B). Because both agents are apoptotic inducers $(11,12,22-26)$, the requirement of caspases in cell killing by each agent and the combination was assessed using the pan caspase inhibitor zVAD-fmk. As shown in Fig. 2B, zVAD-fmk substantially inhibited cell killing after dasatinib, but not after either PDT alone or the combination. Overall, the data demonstrate that each agent induces dose-dependent cell killing, the combination enhances cell killing, and that, unlike PDT alone or the combination, dasatinib induces zVAD-fmkdependent cell killing.

Dasatinib-induced caspase-3 activation is inhibited by zVADfmk. The combination potentiates PDT-or dasatinib-induced activation of caspase-3 in the absence of appearance of other apoptotic markers. Because zVAD-fmk inhibits effector caspases, including caspase-3 (27), we verified caspase-3 as a zVAD-fmk target in dasatinib-induced cell death using DEVDase assay. Caspase- 3 activation began at $2 \mathrm{~h}$ and peaked at $24 \mathrm{~h}$ after dasatinib (not shown). As depicted in Fig. 3A, dasatinib induced activation of DEVDase was abolished by zVAD-fmk. The data suggest that zVAD-fmk-sensitive cell killing after dasatinib involves caspase-3.

To further assess induction of apoptosis after treatments, caspase-3 activation, mitochondrial depolarization and the appearance of Annexin $\mathrm{V}^{+}$and propidium iodide ${ }^{+}$cells were determined. PDT induced a dose-dependent activation of caspase-3 and the effect was potentiated after PDT + dasatinib (Fig. 3B). PDT alone induced mitochondrial depolarization and the effect was inhibited after the combination (Fig. 3C). Annexin $\mathrm{V}^{+}$and/or propidium iodide ${ }^{+}$cells remained at control levels after treatments (Fig. 3D). We validated that SCCVII cells display depolarized mitochondria and undergo apoptosis using camptothecin as a positive control (Fig. 3C and D). The results show that the combined treatment augments PDT or dasatinib-induced caspase- 3 activation in the absence of appearance of other apoptotic markers.

Dasatinib-induced upregulation of $m R N A$ ceramide synthase 1 is enhanced after the combination. Dasatinib upregulates expression levels of ceramide synthase genes 1,2, 5 and 6 (13). We showed that knockdown of ceramide synthase 1 or 6 leads to apoptotic resistance to PDT $(11,12)$. To test whether ceramide synthases are affected by treatments, mRNA levels of ceramide synthases 1, 2 4, 5 and 6 were measured using RT-PCR. As depicted in Fig. 4A, ceramide synthase $1 \mathrm{mRNA}$ levels were upregulated after dasatinib and the effect was further increased after PDT + dasatinib. PDT alone did not significantly increase ceramide synthase 1 levels. None of the treatments had any effect on mRNA levels of ceramide synthase 2, 4, 5 and 6 (Fig. 4A). The data show that dasatinib-induced upregulation of ceramide synthase $1 \mathrm{mRNA}$ levels is enhanced after the combination.

Effects of treatments on the sphingolipid profile. To assess whether enhanced upregulation of ceramide synthase 1 mRNA after PDT + dasatinib is associated with increased ceramide production, ceramide levels were measured using MS. Dasatinib alone induced a modest increase in C20:1- and C22-ceramide but had no effect on total ceramide levels (Table I and Fig. 4B). PDT alone increased the levels of all 12 individual ceramides that were measured, as well as total ceramides. PDT-induced increases in ceramide levels were not, for the most part, further changed after the combination, with the exception of attenuated levels of C26- and C26:1-ceramide after PDT + dasatinib compared to individual treatments (Table I and Fig. 4B).

The effects of treatments on other sphingolipids were also measured by MS and are shown in Table I. Unlike dasatinib, and irrespective of the presence of dasatinib, PDT increased the levels of C16-dihydroceramide, an intermediate from the de novo sphingolipid biosynthesis pathway. Moreover, unlike dasatinib, and irrespective of the presence of dasatinib, PDT induced an $87 \%$ decrease in sphingosine levels. PDT also induced a $62 \%$ decrease in S1P levels, and the effect was not changed after the combination. Overall, the data show that in SCCVII cells PDT induced substantial changes in the sphingolipid profile that were not modulated by the addition of dasatinib.

Acid ceramidase activity is inhibited after PDT. The substantial decrease in sphingosine levels after PDT could result from 

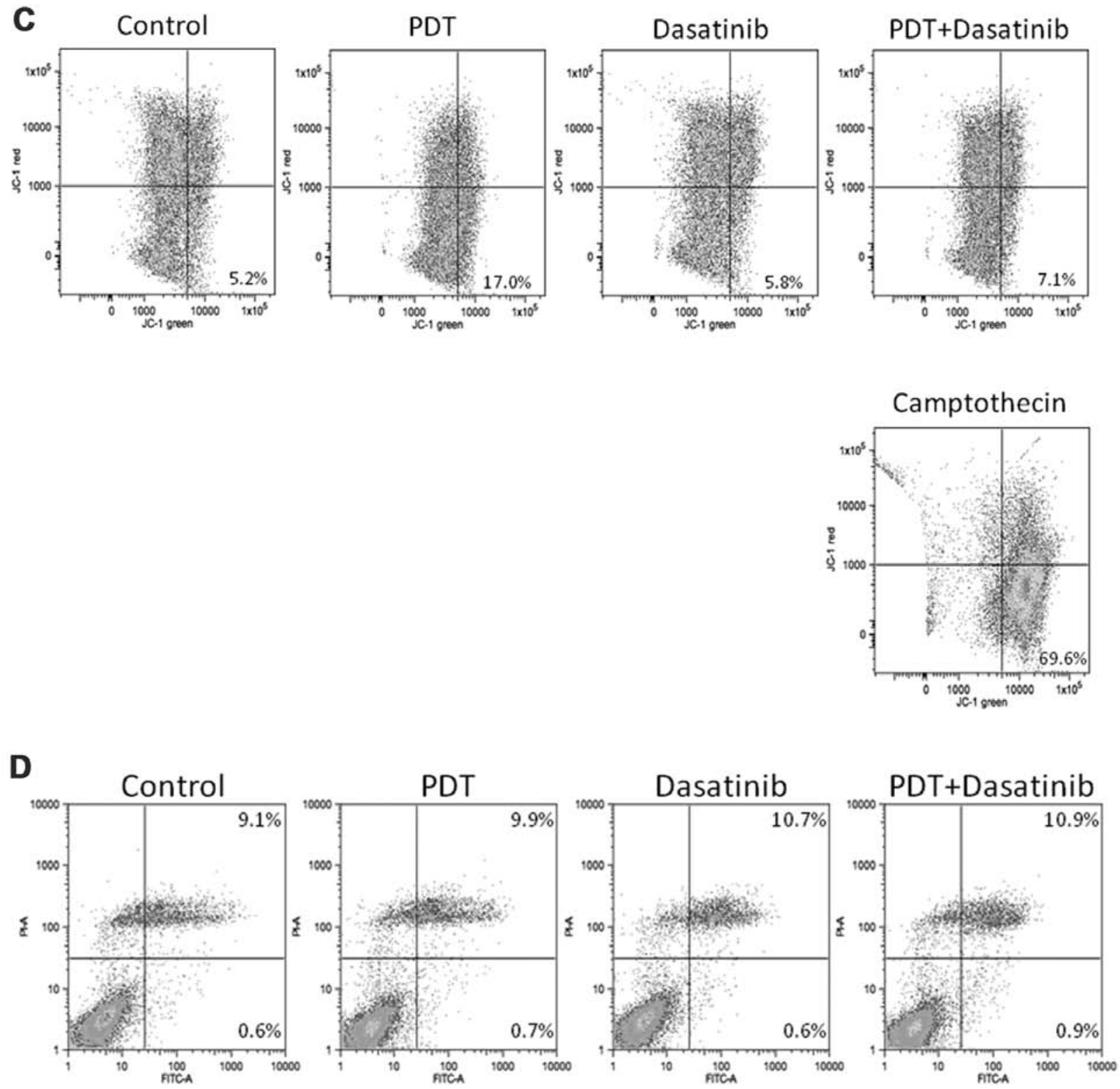

\section{Camptothecin}

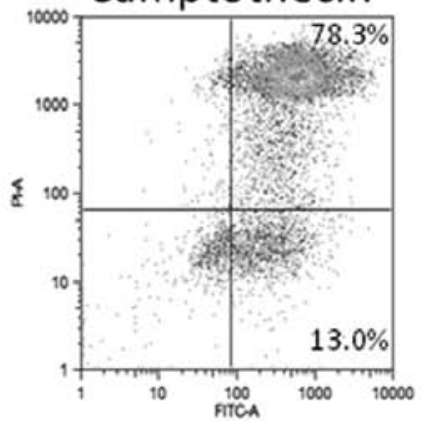

Figure 3. Continued. (C) PDT-induced mitochondrial depolarization is abolished after the combination. (D) Annexin $\mathrm{V}^{+}$and propidium iodide ${ }^{+}$cells remain at control levels after treatments. SCCVII cells were treated with dasatinib (200 nM) for $24 \mathrm{~h}$ (A-C) or $72 \mathrm{~h}$ (D). For PDT, after overnight incubation with Pc 4 (100 or $250 \mathrm{nM})$, cells were irradiated with red light $\left(200 \mathrm{~mJ} / \mathrm{cm}^{2}\right)$ and then incubated for $2 \mathrm{~h}(\mathrm{~B}$ and $\mathrm{C})$ or $48 \mathrm{~h}$ (D). For dasatinib $+\mathrm{zVAD}$-fmk, the inhibitor was added $1 \mathrm{~h}$ prior to dasatinib (A). For PDT + dasatinib, dasatinib was added to the cells $22 \mathrm{~h}$ (B and C) or $24 \mathrm{~h}$ prior to irradiation (D). After incubations, cells were collected, lysed and DEVDase assay was carried out to assess caspase-3 activity (A and B). Alternatively, collected cells were processed for flow cytometry using JC-1 or Annexin V/propidium iodide staining for mitochondrial depolarization (C) and apoptosis detection (D), respectively. (C and D) Cells were treated overnight with camptothecin $(5 \mu \mathrm{M})$. (A and B) The data are shown as the mean \pm SEM, $\mathrm{n}=3-23$. The significance $(\mathrm{p}<0.05)$ is shown as follows: "treated is different from untreated control; ${ }^{+}$(PDT + dasatinib) or (dasatinib + zVAD-fmk) is different from individual treatments. Con, untreated control; Das, dasatinib. (C) Percentage of cells with depolarized mitochondria is shown in lower right dot plot. (D) Percentage of Annexin $\mathrm{V}^{+} /$propidium iodide ${ }^{-}$and Annexin $\mathrm{V}^{+} /$propidium iodide $^{+}$cells is shown in lower right and upper right dot plot, respectively. 

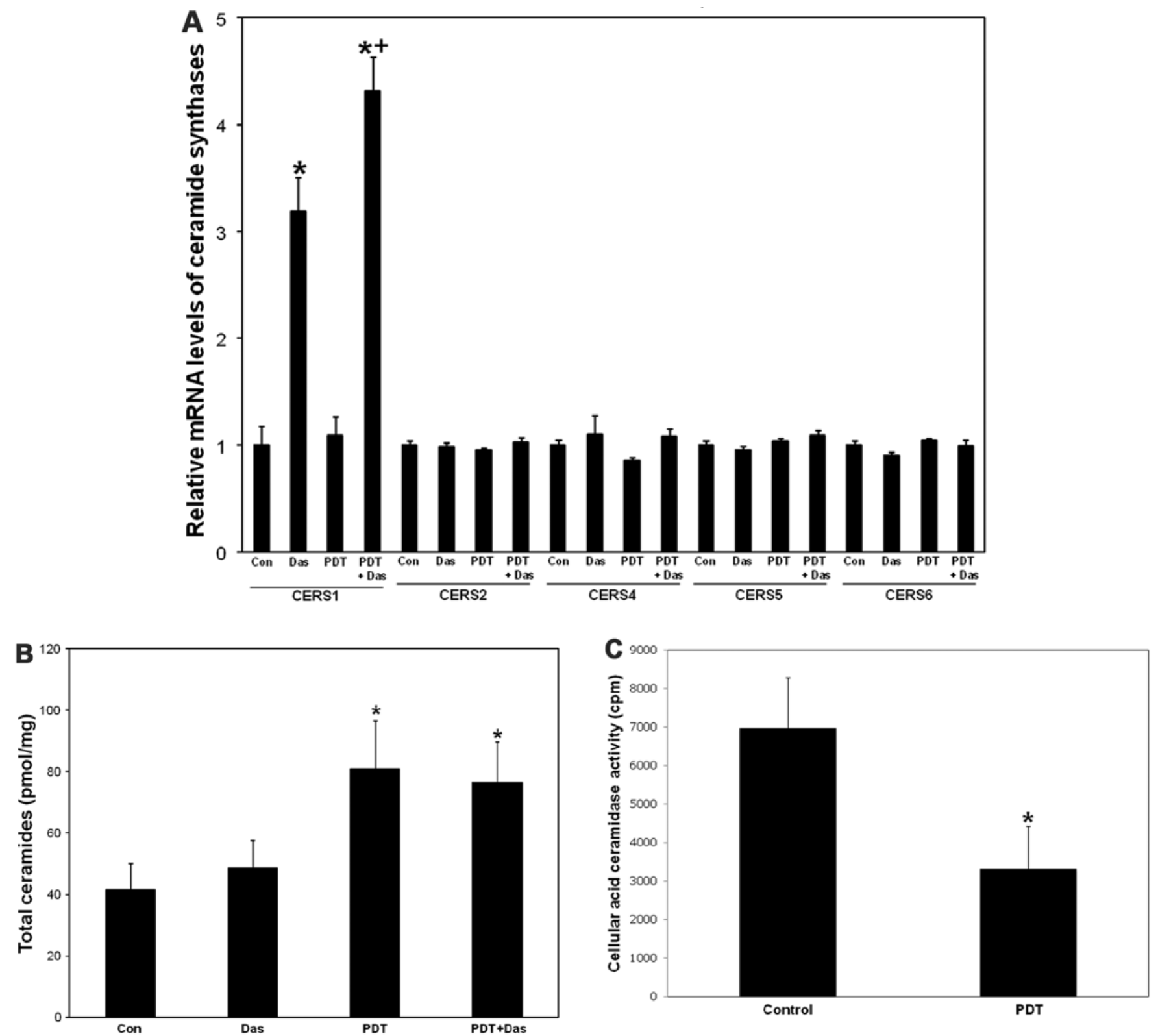

Figure 4. Effect of PDT \pm dasatinib on mRNA levels of ceramide synthases (A) or total ceramide levels (B). (C) Acid ceramidase activity is inhibited after PDT. After PDT with Pc 4 [100 nM (A and B)] or $250 \mathrm{nM}$ (C) and the light fluence of $200 \mathrm{~mJ} / \mathrm{cm}^{2}$, cells were incubated at $37^{\circ} \mathrm{C}$ for $2 \mathrm{~h}$. (A and B) Cells were treated with dasatinib (200 nM) alone for $24 \mathrm{~h}$. For (PDT + dasatinib), dasatinib was added to the cells $22 \mathrm{~h}$ prior to irradiation. After treatments, cells were collected and processed for RT-PCR (A), MS (B) or acid ceramidase assay (C). (A) The data were calculated as: (A) the relative normalized expression of corresponding ceramide synthase mRNAs against the expression of housekeeping gene-encoded proteins RPL37A and HGPRT; (B) pmol/mg protein, and (C) cpm minus background. Control values refer to: (A and B) untreated controls; (C) combined untreated and Pc 4-treated controls. Pc 4 itself had no effect on acid ceramidase activity. All the data are shown as the mean \pm SEM, $n=4-5$. The significance $(\mathrm{p}<0.05)$ is shown as follows: "treated is different from control; ${ }^{+}(\mathrm{PDT}+\mathrm{dasatinib})$ is different from PDT or dasatinib alone. CERS, ceramide synthase; Con, untreated control; Das, dasatinib.

inhibition of ceramidase, a sphingosine-producing enzyme (Fig. 1). The inhibition of acid ceramidase has been implicated in radiosensitization of prostate cancer cells (28). We measured the activity of acid ceramidase in cell lysates from untreated and PDT-treated cells. As depicted in Fig. 4C, acid ceramidase activity was reduced by $52 \%$ post-PDT. Thus, PDT-induced decrease in sphingosine correlated with inhibition of acid ceramidase.

\section{Discussion}

Dasatinib-induced caspase-3 activation and cell killing was zVAD-fmk-dependent. PDT induced caspase-3 activation and the effect was potentiated after the combination. As shown previously (29), PDT-induced caspase-3 activation was abolished by zVAD-fmk. However, PDT- or PDT + dasatinib-induced cell killing was zVAD-fmk-insensitive. zVAD-fmk-insensitivity of PDT is consistent with the findings that caspase- 3 is not required for the lethal effect of PDT (30). Incidentally, zVAD-fmk has been reported to upregulate caspase-9 activity in cell death after etoposide (27). We found no activation of caspase-9 after PDT in SCCVII cells (31). Therefore, it is unlikely that zVAD-fmk would have such an effect, especially since the inhibitor was used in our studies at a non-toxic, and comparably, lower concentration than in the 
Table I. Effect of PDT \pm dasatinib on sphingolipids in SCCVII cells.

\begin{tabular}{|c|c|c|c|c|}
\hline Sphingolipid & Untreated & Dasatinib & PDT & PDT + dasatinib \\
\hline C14-ceramide & $13.1 \pm 1.4$ & $15.2 \pm 1.0$ & $23.6 \pm 1.6^{\mathrm{a}}$ & $21.8 \pm 1.4^{\mathrm{a}}$ \\
\hline C16-ceramide & $94.8 \pm 11.4$ & $103.9 \pm 8.1$ & $196.5 \pm 6.1^{\mathrm{a}}$ & $179.2 \pm 20.4^{\mathrm{a}}$ \\
\hline C18-ceramide & $6.8 \pm 0.9$ & $8.2 \pm 0.5$ & $21.5 \pm 1.6^{\mathrm{a}}$ & $21.5 \pm 1.8^{\mathrm{a}}$ \\
\hline C18:1-ceramide & $4.3 \pm 0.5$ & $4.4 \pm 0.9$ & $10.5 \pm 0.1^{\mathrm{a}}$ & $9.5 \pm 0.6^{\mathrm{a}}$ \\
\hline C20-ceramide & $5.8 \pm 0.8$ & $7.3 \pm 0.7$ & $15.8 \pm 0.6^{\mathrm{a}}$ & $17.6 \pm 0.9^{\mathrm{a}}$ \\
\hline C20:1-ceramide & $0.9 \pm 0.1$ & $1.1 \pm 0.1^{\mathrm{a}}$ & $2.3 \pm 0.2^{\mathrm{a}}$ & $2.5 \pm 0.2^{\mathrm{a}}$ \\
\hline C22-ceramide & $32.5 \pm 3.8$ & $44.7 \pm 3.5^{\mathrm{a}}$ & $80.4 \pm 4.2^{\mathrm{a}}$ & $84.7 \pm 4.7^{\mathrm{a}}$ \\
\hline C22:1-ceramide & $10.0 \pm 1.1$ & $11.2 \pm 1.0$ & $18.4 \pm 0.7^{\mathrm{a}}$ & $17.5 \pm 0.7^{\mathrm{a}}$ \\
\hline C24-ceramide & $147.6 \pm 15.1$ & $172.3 \pm 14.4$ & $270.6 \pm 10.2^{\mathrm{a}}$ & $239.4 \pm 12.2^{\mathrm{a}}$ \\
\hline C24:1-ceramide & $171.7 \pm 18.8$ & $205.3 \pm 15.5$ & $313.0 \pm 14.3^{a}$ & $307.7 \pm 16.6^{\mathrm{a}}$ \\
\hline C26-ceramide & $2.9 \pm 0.3$ & $3.4 \pm 0.3$ & $6.7 \pm 0.3^{a}$ & $5.1 \pm 0.4^{a, b}$ \\
\hline C26:1-ceramide & $4.8 \pm 0.5$ & $5.5 \pm 0.7$ & $11.7 \pm 0.4^{\mathrm{a}}$ & $10.1 \pm 0.5^{\mathrm{a}, \mathrm{b}}$ \\
\hline C16-dihydroceramide & $10.3 \pm 1.5$ & $9.6 \pm 0.6$ & $22.4 \pm 0.5^{\mathrm{a}}$ & $19.7 \pm 1.1^{\mathrm{a}}$ \\
\hline Dihydrosphingosine & $14.2 \pm 2.2$ & $16.9 \pm 1.4$ & $17.2 \pm 1.3$ & $17.4 \pm 0.6$ \\
\hline Dihydrosphingosine-1-phosphate & $0.4 \pm 0.1$ & $0.3 \pm 0.1$ & $0.6 \pm 0.1$ & $0.5 \pm 0.1$ \\
\hline Sphingosine & $118.8 \pm 19.5$ & $150.3 \pm 8.7$ & $15.1 \pm 1.0^{\mathrm{a}}$ & $19.6 \pm 1.8^{\mathrm{a}}$ \\
\hline Sphingosine-1-phosphate & $1.3 \pm 0.1$ & $1.8 \pm 0.2$ & $0.5 \pm 0.1^{\mathrm{a}}$ & $0.7 \pm 0.1^{\mathrm{a}}$ \\
\hline
\end{tabular}

Cells were treated with dasatinib (200 nM) for $22 \mathrm{~h}$ prior to PDT (100 nM Pc $\left.4+200 \mathrm{~mJ} / \mathrm{cm}^{2}\right)$, and then incubated further for $2 \mathrm{~h}$. Afterwards cells were collected and processed for MS. The data were calculated as pmol/mg protein and are shown as the mean \pm SEM ( $n=3-5)$. ${ }^{a}$ Treated is different from untreated control; ${ }^{b}$ PDT + dasatinib is different from individual treatments $(\mathrm{p}<0.05)$.

etoposide study, i.e., 25 vs. $50 \mu \mathrm{M}$, respectively. Overall, the data suggest that, unlike PDT or the combination, dasatinib requires caspase-3 activation for cell killing. Apparently, PDT rather than dasatinib determined zVAD-fmk sensitivity of cell killing after the combination.

Dasatinib-induced upregulation of ceramide synthase 1 mRNA correlated with increased production of C20:1- and C22-ceramide concomitant with activation of caspase-3. This is consistent with the finding that ceramide synthase 1 gene is upregulated during apoptosis after dasatinib (13). However, there was no correlation between combinationinduced enhanced ceramide synthase $1 \mathrm{mRNA}$ upregulation and ceramide production, suggesting that the enzyme might modulate other cellular functions. Ceramide synthase 1 has been associated with sensitization to cisplatin via activation of p38 mitogen-activated protein kinase (MAPK) and concomitant translocation of the enzyme from the endoplasmic reticulum to the Golgi apparatus (32). Activation of p38 MAPK is critical for the antileukemic effects of dasatinib (33). Activation of p38 MAPK pathway has been associated with triggering apoptosis after Pc 4-PDT (34). The potential link between ceramide synthase 1 upregulation, p38 MAPK pathway and sensitization to PDT should be addressed in our future studies.

In HNSCC in vitro and in vivo models ceramide synthase 1-dependent $\mathrm{C} 18$-ceramide production has a proapoptotic role (35) and inhibits xenograft growth (36), respectively. We showed in HNSCC cells that knockdown of CERS1 induced apoptotic resistance to PDT and reduced the levels of total ceramide and several individual ceramides, including
C18-ceramide (12). Our findings that the levels of the whole spectrum of ceramides are increased after PDT in the absence of upregulation of ceramide synthase mRNAs imply the involvement of other enzymes. Accordingly, in the present study we have demonstrated that PDT-induced inhibition of acid ceramidase correlates with decrease in sphingosine and increase in ceramide levels, concomitant with activation of caspase-3. Consistent with these findings, upregulation of acid ceramidase confers radioresistance in prostate cancer cells (28). As suggested in the same study, inhibition of acid ceramidase could be a potential target for treatment of cancers with overexpressed acid ceramidase.

The present study shows for the first time enhanced additive killing of SCCVII cells after the combination of PDT and dasatinib and paves the way for testing the combination in vivo. This combination has the potential to achieve what is hoped by combination therapy, i.e. maximizing the efficacy of each single anticancer agent while minimizing their systemic toxicity through the delivery of lower drug doses (37). This will have to be validated in vivo. Regardless, our novel findings imply the translational potential of the combination for cancer treatment.

\section{Acknowledgements}

This study was supported by U.S. Public Health Service Grants: to D.S., R01 CA77475 from the National Cancer Institute (NCI), National Institutes of Health (NIH); to J.M.K., P20-RR17677 (NIH), grants from the Rally Foundation for Childhood Cancer Research, Hyundai Hope on Wheels, Monica Kreber 
Golf Tournament, and Chase after a Cure Foundation; to T.I.G., the Veterans Administration Merit Awards from RR\&D and BLRD programs; to the flow cytometry-related work at the Microscopy, Imaging, and Cytometry Resources Core (Karmanos Cancer Institute, Wayne State University), NCI Grant P30 CA22453; to the MS-related work at the Lipidomics Shared Resource (Medical University of South Carolina), NCI Grants IPO1CA097132 and P30 CA 138313, NIH/NCRR SC COBRE Grant P20 RR017677, C06 RR018823 from the Extramural Research Facilities Program of the National Center for Research Resources.

\section{References}

1. Agostinis P, Berg K, Cengel KA, Foster TH, Girotti AW, Gollnick SO, Hahn SM, Hamblin MR, Juzeniene A, Kessel D, Korbelik M, Moan J, Mroz P, Nowis D, Piette J, Wilson BC and Golab J: Photodynamic therapy of cancer: an update. CA Cancer J Clin 61: 250-281, 2011.

2. Wei G, Rafiyath S and Liu D: First-line treatment for chronic myeloid leukemia: dasatinib, nilotinib, or imatinib. J Hematol Oncol 3: 47, 2010.

3. Brooks HD, Glisson BS, Bekele BN, Johnson FM, Ginsberg LE, El-Naggar A, Culotta KS, Takebe N, Wright J, Tran HT and Papadimitrakopoulou VA: Phase 2 study of dasatinib in the treatment of head and neck squamous cell carcinoma. Cancer 117: 2112-2119, 2012.

4. Kopetz S, Lesslie DP, Dallas NA, Park SI, Johnson M, Parikh NU, Kim MP, Abbruzzese JL, Ellis LM, Chandra J and Gallick GE: Synergistic activity of the SRC family kinase inhibitor dasatinib and oxaliplatin in colon carcinoma cells is mediated by oxidative stress. Cancer Res 69: 3842-3849, 2009.

5. Pichot CS, Hartig SM, Xia L, Arvanitis C, Monisvais D, Lee FY, Frost JA and Corey SJ: Dasatinib synergizes with doxorubicin to block growth, migration, and invasion of breast cancer cells. Br J Cancer 101: 38-47, 2009.

6. Haura EB, Tanvetyanon T, Chiappori A, Williams C, Simon G, Antonia S, Gray J, Litschauer S, Tetteh L, Neuger A, Song L, Rawal B, Schell MJ and Bepler G: Phase I/II study of the Src inhibitor dasatinib in combination with erlotinib in advanced non-small-cell lung cancer. J Clin Oncol 28: 1387-1394, 2010.

7. Raju U, Riesterer O, Wang ZQ, Molkentine DP, Molkentine JM, Johnson FM, Glisson B, Milas L and Ang KK: Dasatinib, a multikinase inhibitor increased radiation sensitivity by interfering with nuclear localization of epidermal growth factor receptor and by blocking DNA repair pathways. Radiother Oncol 105: 241-249, 2012.

8. Adan-Gokbulut A, Kartal-Yandim M, Iskender G and Baran Y: Novel agents targeting bioactive sphingolipids for the treatment of cancer. Curr Med Chem 20: 108-122, 2013.

9. Hannun YA and Obeid LM: Many ceramides. J Biol Chem 286: 27855-27862, 2011.

10. Saddoughi SA and Ogretmen B: Diverse functions of ceramide in cancer cell death and proliferation. Adv Cancer Res 117: 37-58, 2013.

11. Separovic D, Breen P, Joseph N, Bielawski J, Pierce JS, Van Buren E and Gudz TI: Ceramide synthase 6 knockdown suppresses apoptosis after photodynamic therapy in human head and neck squamous carcinoma cells. Anticancer Res 32: 753-760, 2012.

12. Separovic D, Breen P, Joseph N, Bielawski J, Pierce JS, Van Buren E and Gudz TI: siRNA-mediated down-regulation of ceramide synthase 1 leads to apoptotic resistance in human head and neck squamous carcinoma cells after photodynamic therapy. Anticancer Res 32: 2479-2485, 2012.

13. Gencer EB, Ural AU, Avcu F and Baran Y: A novel mechanism of dasatinib-induced apoptosis in chronic myeloid leukemia; ceramide synthase and ceramide clearance genes. Ann Hematol 90: $1265-1275,2011$

14. Khurana D, Martin EA, Kasperbauer JL, O'Malley BW Jr, Salomao DR, Chen L and Strome SE: Characterization of a spontaneously arising murine squamous cell carcinoma (SCC VII) as a prerequisite for head and neck cancer immunotherapy. Head Neck 23: 899-906, 2001.
15. Suit HD, Sedlacek RS, Silver G and Dosoretz D: Pentobarbital anesthesia and the response of tumor and normal tissue in the C3Hf/sed mouse to radiation. Radiat Res 104: 47-65, 1985.

16. Separovic D, Semaan L, Tarca AL, Awad Maitah MY, Hanada K, Bielawski J, Villani M and Luberto C: Suppression of sphingomyelin synthase 1 by small interference RNA is associated with enhanced ceramide production and apoptosis after photodamage. Exp Cell Res 314: 1860-1868, 2008.

17. Bai A, Szulc ZM, Bielawski J, Mayroo N, Liu X, Norris J, Hannun YA and Bielawska A: Synthesis and bioevaluation of omega-N-amino analogs of B13. Bioorg Med Chem 17: 1840-1848, 2009.

18. Dolgachev V, Farooqui MS, Kulaeva OI, Tainsky MA, Nagy B, Hanada K and Separovic D: De novo ceramide accumulation due to inhibition of its conversion to complex sphingolipids in apoptotic photosensitized cells. J Biol Chem 279: 2323823249, 2004

19. Dolgachev V, Nagy B, Taffe B, Hanada K and Separovic D: Reactive oxygen species generation is independent of de novo sphingolipids in apoptotic photosensitized cells. Exp Cell Res 288: 425-436, 2003.

20. Separovic D, Saad ZH, Edwin EA, Bielawski J, Pierce JS, Van Buren E and Bielawska A: C16-ceramide analog combined with Pc 4 photodynamic therapy evokes enhanced total ceramide accumulation, promotion of DEVDase activation in the absence of apoptosis, and augmented overall cell killing. J Lipids 2011: $1-9,2011$

21. Separovic D, Mann KJ and Oleinick NL: Association of ceramide accumulation with photodynamic treatment-induced cell death Photochem Photobiol 68: 101-109, 1998.

22. Agarwal ML, Clay ME, Harvey EJ, Evans HH, Antunez AR and Oleinick NL: Photodynamic therapy induces rapid cell death by apoptosis in L5178Y mouse lymphoma cells. Cancer Res 51: 5993-5996, 1991.

23. Wispriyono B, Schmelz E, Pelayo H, Hanada K and Separovic D: A role for the de novo sphingolipids in apoptosis of photosensitized cells. Exp Cell Res 279: 153-165, 2002.

24. Nam S, Williams A, Vultur A, List A, Bhalla K, Smith D, Lee FY and Jove R: Dasatinib (BMS-354825) inhibits Stat5 signaling associated with apoptosis in chronic myelogenous leukemia cells. Mol Cancer Ther 6: 1400-1405, 2007.

25. Lin YC, Wu MH, Wei TT, Chuang SH, Chen KF, Cheng AL and Chen CC: Degradation of epidermal growth factor receptor mediates dasatinib-induced apoptosis in head and neck squamous cell carcinoma cells. Neoplasia 14: 463-475, 2012.

26. Xue T, Luo P, Zhu H, Zhao Y, Wu H, Gai R, Wu Y, Yang B, Yang $\mathrm{X}$ and He Q: Oxidative stress is involved in Dasatinibinduced apoptosis in rat primary hepatocytes. Toxicol Appl Pharmacol 261: 280-291, 2012.

27. Rodriguez-Enfedaque A, Delmas E, Guillaume A, Gaumer S, Mignotte B, Vayssiere JL and Renaud F: zVAD-fmk upregulates caspase- 9 cleavage and activity in etoposide-induced cell death of mouse embryonic fibroblasts. Biochim Biophys Acta 1823: 1343-1352, 2012

28. Mahdy AE, Cheng JC, Li J, Elojeimy S, Meacham WD, Turner LS, Bai A, Gault CR, McPherson AS, Garcia N, Beckham TH, Saad A, Bielawska A, Bielawski J, Hannun YA, Keane TE, Taha MI, Hammouda HM, Norris JS and Liu X: Acid ceramidase upregulation in prostate cancer cells confers resistance to radiation: AC inhibition, a potential radiosensitizer. Mol Ther 17: 430-438, 2009.

29. Nagy B, Chiu S-M and Separovic D: Fumonisin B1 does not prevent apoptosis in A431 human epidermoid carcinoma cells after photosensitization with phthalocyanine 4. J Photochem Photobiol B 57: 132-141, 2000

30. Xue LY, Chiu SM and Oleinick NL: Photodynamic therapyinduced death of MCF-7 human breast cancer cells: a role for caspase- 3 in the late steps of apoptosis but not for the critical lethal event. Exp Cell Res 263: 145-155, 2001

31. Separovic D, Joseph N, Breen P, Bielawski J, Pierce JS, van Buren E, Bhatti G, Saad ZH, Bai A and Bielawska A: Combining anticancer agents photodynamic therapy and LCL85 leads to distinct changes in the sphingolipid profile, autophagy, caspase- 3 activation in the absence of cell death, and long-term sensitization. Biochem Biophys Res Commun 409: 372-377, 2011.

32. Min J, Mesika A, Sivaguru M, Van Veldhoven PP, Alexander H, Futerman AH and Alexander S: (Dihydro)ceramide synthase 1 regulated sensitivity to cisplatin is associated with the activation of p38 mitogen-activated protein kinase and is abrogated by sphingosine kinase 1. Mol Cancer Res 5: 801-812, 2007. 
33. Dumka D, Puri P, Carayol N, Lumby C, Balachandran H, Schuster K, Verma AK, Terada LS, Platanias LC and Parmar S: Activation of the p38 Map kinase pathway is essential for the antileukemic effects of dasatinib. Leuk Lymphoma 50: 2017-2029, 2009.

34. Whitacre CM, Feyes DK, Satoh T, Grossmann J, Mulvihill JW, Mukhtar H and Oleinick NL: Photodynamic therapy with the phthalocyanine photosensitizer Pc 4 of SW480 human colon cancer xenografts in athymic mice. Clin Cancer Res 6: 2021-2027, 2000 .
35. Koybasi S, Senkal CE, Sundararaj K, Spassieva S, Bielawski J, Osta W, Day TA, Jiang JC, Jazwinski SM, Hannun YA, Obeid LM and Ogretmen B: Defects in cell growth regulation by C18:0ceramide and longevity assurance gene 1 in human head and neck squamous cell carcinomas. J Biol Chem 279: 44311-44319, 2004.

36. Senkal CE, Ponnusamy S, Bielawski J, Hannun YA and Ogretmen B: Antiapoptotic roles of ceramide-synthase-6-generated C16-ceramide via selective regulation of the ATF6/CHOP arm of ER-stress-response pathways. FASEB J 24: 296-308, 2010.

37. Mayer LD and Janoff AS: Optimizing combination chemotherapy by controlling drug ratios. Mol Interv 7: 216-223, 2007. 